Original Article

\title{
Using Ultrasonic Acoustics to Detect Cryptic Flying Squirrels: Effects of Season and Habitat Quality
}

\author{
CORINNE A. DIGGINS (D, ${ }^{1}$ Department of Fish and Wildlife Conservation, Virginia Polytechnic Institute and State University, Blacksburg, \\ VA 24061, USA \\ L. MICHELLE GILLEY, Department of Natural Sciences, Mars Hill University, Mars Hill, NC 28754, USA \\ CHRISTINE A. KELLY, Wildife Management Division, North Carolina Wildlife Resources Commission, Asheville, NC 28803, USA \\ W. MARK FORD, U.S. Geological Survey, Virginia Cooperative Fish and Wildlife Research Unit, Blacksburg, VA 24061, USA
}

\begin{abstract}
New technologies allow for more efficient and effective monitoring of rare or elusive species. However, standardizing protocol to ensure high detection rates is important prior to widespread use of a new technique. The use of ultrasonic acoustic detectors to survey for flying squirrels (Glaucomys spp.) is a novel method that is more efficient than traditional methods. However, certain methodologies for this technique still need to be refined. During 2015, we conducted a seasonal and habitat quality study on the endangered Carolina northern flying squirrel ( $G$. sabrinus coloratus) in western North Carolina, USA. Our seasonal study examined differences in probability of detection (POD) and latency to detection (LTD) at 30 high-quality sites across 10 survey nights in spring, summer, and autumn. The habitat quality study focused on POD and LTD among 15 sites with varying habitat quality (5 High, 5 Medium, 5 Low) across 20 survey nights. We found POD similar between seasons, with POD 15-20\% greater during spring. The LTD was comparable among seasons. We found that POD and LTD varied at sites with different habitat quality. The POD was similar between High and Medium sites $(0.26 \pm 0.04 \mathrm{SE}$ and $0.29 \pm 0.05$, respectively), but greater than Low sites $(0.02 \pm 0.02)$. The LTD was not different among sites with differing habitat quality, although LTD at High sites was 2.7 and 4.5 times lower than Medium and Low sites, respectively. Trill calls, the most distinctive species-specific call type produced by species of flying squirrels, was recorded at greater rates in spring versus other times of the year. Our results indicate flying squirrels can be surveyed during any season, although habitat quality needs to be considered when determining survey length. For Carolina northern flying squirrel, the optimal time to perform acoustic surveys is during the spring season for 6-10 survey nights at sites with high or medium habitat quality. (C) 2020 The Wildlife Society.
\end{abstract}

KEY WORDS detection probability, Glaucomys sabrinus coloratus, Glaucomys volans, monitoring, survey techniques.

Monitoring is key to the successful management and conservation of wildlife. Nocturnal and cryptic species are inherently more challenging to monitor because of their secretive habits that invariably make them more difficult to observe, resulting in lower detection rates (MacKenzie et al. 2005). Therefore, techniques and methods that increase detectability of these species are crucial to understanding factors, such as distribution and occupancy trends, that may inform management decisions (Pollock et al. 2002, Gu and Swihart 2004, McDonald 2004). Whereas some nocturnal or cryptic species are difficult to monitor using traditional

Received: 24 April 2019; Accepted: 17 December 2019 Published:

\footnotetext{
${ }^{1}$ Email: cordie1@vt.edu
}

techniques, improvements in technology allow for more effective and efficient passive monitoring of these species (Taylor et al. 2014, McDonald et al. 2015, Diggins et al. 2016). However, when introducing a new technique to monitor wildlife, protocols should be developed to maximize efficiency and increase detection rates, especially in the case of rare or endangered species (McDonald 2004, Kelly 2008).

A variety of factors can influence detection rates for a specific technique: variation in orientation and placement of equipment, equipment type and settings, number and arrangement of equipment on the landscape, time of year surveys occur, survey length, structure of the physical environment, and weather (Weller and Zabel 2002, Crimmins et al. 2009, Adams et al. 2012, Coleman et al. 2014, Froidevaux et al. 2014). Although the ecology, natural history, and behavior of species should be the main factors 
directing how studies are designed, it is also important to consider the assumptions and limitations of different study designs by understanding how varying methodologies may influence detection rates (Hayes 2000, Gooch et al. 2006, Foster and Harmsen 2012, Britzke et al. 2013). Additionally, methodologies must be adapted to enhance the effectiveness of a survey technique for new taxonomic groups regardless of the past success of the technique for other taxonomic groups (e.g., Glen et al. 2013, Taylor et al. 2014).

Ultrasonic acoustics has been a popular method to survey bat communities in the field over the past 3 decades and recent research has shown this technique may be a valuable survey tool for other terrestrial mammals that produce ultrasonic calls (Britzke et al. 2013). Ultrasonic vocalizations of nonvolant mammals are relatively understudied outside common species of rodents used in laboratory research (Sales 2010). However, interest in cataloging call repertoires of captive wild species has increased, allowing for ultrasonic acoustics to be applied as a survey technique for those species in the wild (Kalcounis-Rueppell et al. 2010, Soltis et al. 2012, Gilley et al. 2019). Increasingly, ultrasonic acoustics has been adapted in field studies for nonvolant mammals (KalcounisRueppell et al. 2006, Wilson and Hare 2006, Gilley 2013, Petric and Kalcounis-Rueppell 2013, Diggins et al. 2016). Although ultrasonic acoustic surveys do not allow for population estimates of individuals, these types of surveys allow researchers to more rapidly determine other ecologically important information, such as current distribution, spatial and temporal occupancy rates, activity patterns, and species richness (Hayes 2000, Gibb et al. 2018).

American flying squirrels (Glaucomys spp.) are known to emit ultrasonic vocalizations (Wells-Gosling 1985). However, categorization of vocal repertoires has only occurred recently (Gilley 2013, Eisinger et al. 2016, Gilley et al. 2019). Flying squirrels produce species-specific calls that can be used to differentiate them in the wild in areas of sympatry (Gilley 2013, Diggins and Ford 2017). Additionally, this method is considered one of the most effective and efficient ways to survey for endangered subspecies of flying squirrels compared with traditional methods on account of greater detection rates (Reynolds et al. 1999; Diggins et al. 2016, 2017). Camera-trapping is an effective passive surveying technique that has comparable detection rates to acoustic surveys, but it is currently difficult to differentiate between species of flying squirrels using this method; whereas, acoustics has species-specific calls that can be easily distinguished (Boulerice and Van Fleet 2016, Diggins et al. 2016, Gilley et al. 2019). Similar to camera traps, acoustics are still a novel survey technique for flying squirrels and further methodologies for both techniques need to be developed. Although certain methodologies borrowed from bat acoustic surveys can be applied to flying squirrel acoustic surveys, such as weatherproofing and detector orientation, a more specific protocol needs to be determined to increase the efficiency and effectiveness of this technique (Weller and Zabel 2002, Britzke et al. 2010).

The Carolina northern flying squirrel ( $G$. sabrinus coloratus) is an arboreal, nocturnal Sciurid that was listed as federally endangered in 1984 under the 1973 Endangered Species Act (as amended, ESA; USFWS 1985). The Carolina northern flying squirrel occurs in high-elevation sky islands of montane conifer (e.g., red spruce [Picea rubens], Fraser fir [Abies fraseri]), and montane conifer-northern hardwood forests of the southern Appalachian Mountains in southwestern Virginia, eastern Tennessee, and western North Carolina, USA (USFWS 1985; Weigl et al. 1992; Ford et al. 2014, 2015; Diggins et al. 2017). This subspecies is difficult to monitor using traditional techniques (i.e., livetrapping and nest boxes) because of low capture rates (Reynolds et al. 1999, Ford et al. 2015). However, ultrasonic acoustics recently has been shown to be an effective and efficient way to successfully monitor this endangered subspecies compared with live-trapping and camera-trapping, whereas the former has drastically lower detection rates and the latter currently cannot be used to differentiate Carolina northern flying squirrel from sympatric southern flying squirrels ( $G$. volans; Diggins et al. 2016). Ultrasonic acoustic field surveys for the Carolina northern flying squirrel began in 2010, although aspects of when to survey and the duration therein are unknown (Gilley 2013).

Timing of surveys is important because seasonal variation may influence detection, even in species that reside at the site year-round (Crimmins et al. 2009, Vine et al. 2009, Greene et al. 2016). Detection rates of species at a site rarely are constant spatially or temporally, typically varying as a result of demographic (e.g., fluctuations in population levels), environmental (e.g., weather inducing torpor, hibernation, or migration; food availability), or behavioral factors (e.g., territory establishment, reduction of home range size corresponding to rearing of young). Flying squirrel behavior (e.g., dispersal, social group dynamics, activity patterns) and population demographics are influenced by time of year (Muul 1968, Wells-Gosling 1985, Weigl et al. 1992). Therefore, conducting survey efforts during the time of year when detection rates are greatest may be critical to increasing probability of detection of flying squirrels and providing managers with accurate distributional data.

Likewise, effort can influence the probability of detection of a species at a site, whereby insufficient sampling efforts can lead to an underestimation of occupancy $(\mathrm{Gu}$ and Swihart 2004). The length that equipment is deployed can influence whether a species is detected at that site, so ensuring studies are employing the correct minimum survey length to detect a species is important to reduce false absences (Froidevaux et al. 2014, Taylor et al. 2014). Additionally, because Carolina northern flying squirrels are restricted to high-elevation sky islands and habitat occupancy is related to the amount of overstory montane conifer, habitat quality may influence detection rates (Ford et al. 2015, Diggins et al. 2017). Therefore, surveys in high-quality habitat such as pure spruce-fir stands may require shorter survey lengths than surveys at lower elevation sites dominated by northern hardwood species and considered lower quality habitat (Ford et al. 2010, 2015; Diggins et al. 2017). To understand how spatial and temporal factors may influence detection rates of the Carolina northern flying squirrel, we conducted 2 related 
studies to compare 1) seasonal detection rates in high-quality habitat to determine the best time of year to survey, and 2) detection rates in areas with varying habitat quality to determine minimum survey length in relation to habitat.

\section{STUDY AREAS}

Our acoustic studies occurred in high-elevation sky islands in the Blue Ridge Sub-physiographic Province of the Southern Appalachian Mountains in western North Carolina (Fig. 1). Pure spruce-fir forests occurred above $>1,525 \mathrm{~m}$ and were distributed on the highest peaks and ridgelines in the Southern Appalachians. Fraser fir was the dominate canopy species above $1,825 \mathrm{~m}$, while the canopy mainly consisted of red spruce between 1,525 and $1,825 \mathrm{~m}$. Other species that occurred at lower frequencies in this forest type included yellow birch (Betula alleghaniensis), American mountain ash (Sorbus americana), and mountain maple (Acer spicatum). Understory species included Catawba rhododendron (Rhododendron catawbiense), blueberry shrubs (Vaccinium spp.), and viburnum shrubs (Viburnum spp.), while ground cover was dominated by ferns, mosses, grasses, and spruce-fir regeneration. Lower elevation sites $(1,220-1,525 \mathrm{~m})$ included spruce-northern hardwood forests and stands dominated by northern hardwood and montane northern red oak (Quercus rubra) forests. Northern hardwood forest overstories were composed of American beech (Fagus grandifolia), yellow birch, yellow buckeye (Aesculus flava), and sugar maple (Acer saccharum). Pure northern hardwood forests occurred between 1,220 and $1,370 \mathrm{~m}$, while above $1,370 \mathrm{~m}$ they became co-dominate with red spruce, which increased in dominance in the canopy with increased elevation. Northern red oak forests had canopies dominated by red oak, often with chestnut oak (Q. montana), red maple (Acer rubrum), and tulip poplar (Liriodendron tulipifera) and occurred between 1,220 and $1,370 \mathrm{~m}$. Understories of both northern hardwood and red oak forests included rhododendron, blueberry shrubs, mountain laurel (Kalmia latifolia) and alternateleaf dogwood (Cornus alternifolia), and had dense herbaceous ground cover. Both northern hardwood forests and montane northern red oak forests represented low-quality habitat for Carolina northern flying squirrels (Diggins et al. 2017). All of the sites we surveyed were cut during the industrial logging period around the turn of the 20th Century and were all second-growth forests. Our study sites were characterized by cold winters and mild summers (average temperatures ranging from $-4^{\circ}$ to $16^{\circ} \mathrm{C}$ and $15^{\circ}$ to $30^{\circ} \mathrm{C}$, respectively), large amounts of precipitation $(150-200 \mathrm{~cm}$ annually), and low cloud deposition (during $30-50 \%$ of the year).

\section{METHODS}

\section{Seasonal Study}

For our seasonal study, we selected 10 study areas in pure spruce-fir forests in 6 of the 9 ESA Geographical Recovery Areas (GRAs; USFWS 1990; Fig. 1). These forests were

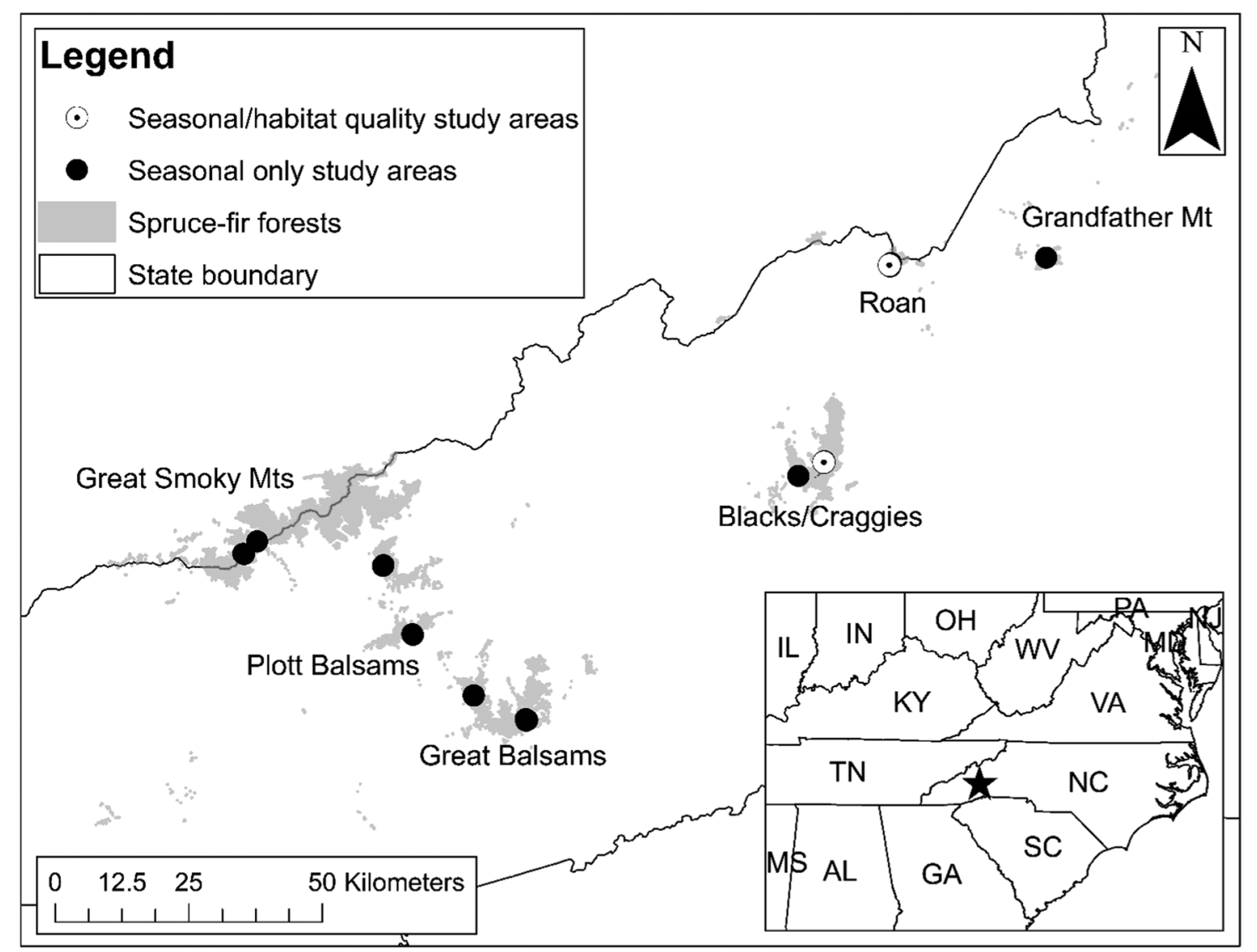

Figure 1. Location of Carolina northern flying squirrel ultrasonic acoustic study areas in western North Carolina, USA, during 2015. 
the selected habitat of the Carolina northern flying squirrel and where the highest quality habitat for this species occurred (Payne et al. 1989; Ford et al. 2014, 2015; Diggins et al. 2017). Additionally, these areas occurred at elevations that excluded the occupancy of the southern flying squirrel. This species was sympatric with the Carolina northern flying squirrel at lower elevation sites where habitat was dominated by northern hardwood and montane northern red oak, both of which represented lower quality habitat for the Carolina northern flying squirrel (Diggins et al. 2017). Study areas averaged $1,722 \pm 34 \mathrm{~m}$ in elevation (range = $1,590-1,894 \mathrm{~m}$ ).

We conducted acoustic surveys in late April-May, July-early August, and late September-October 2015 (hereafter spring, summer, and autumn, respectively). Although Carolina northern flying squirrels were active year-round and did not hibernate (Wells-Gosling and Heaney 1984), we did not survey during winter months because of the lack of access to these high-elevation sites. Moreover, ultrasonic detectors used in our study have high failure rates when temperatures are $\leq 0^{\circ} \mathrm{C}$. We randomly selected 3 sites/study area and placed one Pettersson D500x ultrasonic acoustic detector (Pettersson Elecktronic $\mathrm{AB}$, Uppsala, Sweden) at each survey site $(N=30$ survey sites; Fig. 1). The D500x was a full-spectrum detector with a directional microphone that recorded in real time and stored call files with timestamps onto compact flash (CF) cards. Based on known home-range sizes of the Carolina northern flying squirrel in high-quality habitat, we placed survey sites $\geq 50 \mathrm{~m}$ (average $137.8 \mathrm{~m} \pm 30.6$, range $=50-581$ ) away from each other to ensure independence between detectors (Ford et al. 2014; Diggins et al. 2016, 2017). We programmed detectors to operate between sunset and sunrise, reducing unnecessary recording of call files that would accumulate during diurnal surveys. This allowed for multinight passive sampling with detailed temporal data. We surveyed sites for 2 -night periods during each season ( $n=10$ survey nights/season). We placed detectors in steel ammunition boxes $(30.5 \times$ $15.6 \times 19 \mathrm{~cm}$; model MA21; BLACKHAWK!, Overland Park, KS, USA) fitted with a 5-cm-wide, $35^{\circ}$ elbow, polyvinyl chloride tube for weatherproofing and to protect from black bear (Ursus americanus) damage (Britzke et al. 2010, Diggins et al. 2016). We attached detectors $1.5 \mathrm{~m}$ high on the bole of a tree with bungee cords and oriented detectors at canopy gaps or areas with reduced clutter (i.e., vegetation) in the understory and midstory to allow for better recording (Fig. 2; Weller and Zabel 2002, Diggins et al. 2016). The Virginia Tech Institutional Animal Care and Use Committee approved our methods for acoustic surveys (permit \#11-120-FIW).

\section{Habitat Quality Study}

We conducted the habitat quality study during June 2015 in spruce-fir, spruce-northern hardwood, and northern hardwood forests at the Roan Mountain Highlands and Black Mountains study areas (Fig. 1). Using the Carolina northern flying squirrel occupancy map created by Ford

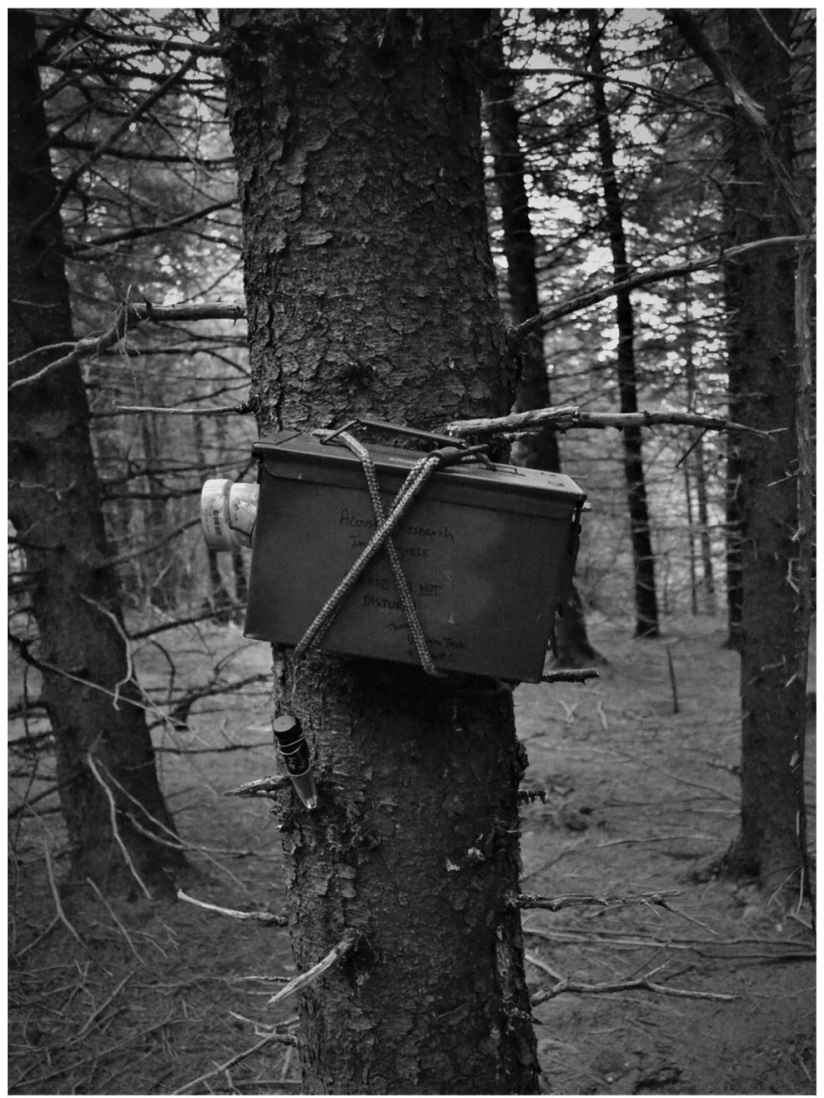

Figure 2. Example of the set-up of an ultrasonic detector used for Carolina northern flying squirrel surveys during 2015 in western North Carolina, USA.

et al. (2015) with data from 15 years of range-wide nest-box surveys in 7 of the 9 GRAs, we randomly placed detectors in 3 areas of relative habitat quality: High ( $>50 \%$ potential habitat), Medium (10-50\% potential habitat), and Low $(<10 \%$ potential habitat). At certain sites (especially Medium and Low sites), Carolina northern flying squirrels often were sympatric with southern flying squirrels, where the latter increased in occupancy at sites with smaller amounts of overstory montane conifer and increased northern hardwood and montane oak components (Weigl et al. 1992). However, these species were differentiated by their ultrasonic vocalizations, allowing for field surveys where the 2 species were sympatric (Gilley 2013, Diggins et al. 2016, Diggins and Ford 2017, Gilley et al. 2019). We surveyed 15 sites within the 2 study areas: 5 High, 5 Medium, and 5 Low (Fig. 1). We randomly located acoustic sites approximately $50 \mathrm{~m}$ from edges between patches with different habitat quality categories and placed each site $>250 \mathrm{~m}$ away from each other $(\overline{\mathrm{x}}=1,483 \mathrm{~m} \pm 259$, range $=376-3,359)$. Using the same detector model, weatherproofing, detector height, sunset to sunrise timer, and orientation set-up as the seasonal study, we placed one detector at each site. We surveyed all sites simultaneously for 20 consecutive days to reduce temporal variation between sites. We visited sites every 6-7 days to change batteries and check $\mathrm{CF}$ cards. 


\section{Data Analysis}

Prior to conducting call file analysis, we ran all acoustic data through Sonobat Scrubber 5.4 (DND Design, Arcata, CA, USA) and removed files that did not contain acoustic calls (i.e., noise files from wind or rain). Files that remained after scrubbing included calls of flying squirrels as well as insects, bats (Chiroptera), mice (Peromyscus spp.), other animals, and some extraneous noises, such as rain, that failed to be scrubbed. We sorted all remaining files into flying squirrel and non-flying squirrel calls visually and audibly by looking at spectrograms and playing calls at time expansion factor of 10 in SonoBat 2.9.8 (DND Design). We used a call library of captive and wild flying squirrels to confirm calls to species (Gilley 2013, Gilley et al. 2019). For Carolina northern flying squirrels and southern flying squirrels, we recorded the call type, and the time and date of each call file for each species.

To determine the influence of season and habitat quality on acoustic monitoring of Carolina northern flying squirrels, we assessed the probability of detection (POD) and the latency to detection (LTD) at each site. We determined POD using an occupancy modeling framework, where $P$ is the probability a species is detected at a site given that it is present and $\psi$ is the probability that a species occurred within an area (MacKenzie et al. 2005). Occupancy modeling used a maximum likelihood approach to estimate the probability of detecting a species given it is present at a site with the assumption that the detectability of that species remains constant during the study period (MacKenzie et al. 2002). To determine the effects of seasonality and habitat occupancy on POD, we used season and habitat quality categories, respectively, to determine differences in detection probability for each study. We conducted a multiseason model for the seasonal study and a single-season model for the survey length study in Program PRESENCE 12.24 to determine POD between seasons and habitat quality (Hines 2018).

To determine variation in survey efficiency, we used LTD (i.e., the no. of survey nights needed to obtain an initial detection of a focal species at a site; Gompper et al. 2006) using the assumption that lower LTDs signifies more efficient surveys. All acoustic data had time stamps; therefore, we were able to measure LTD for each survey site and compared seasons and habitat quality. To determine whether POD and LTD varied among seasons or habitat quality categories, we analyzed differences using nonparametric Kruskal-Wallis and Wilcoxon Rank-Sum tests in Program R 3.1 (R Development Core Team 2015). We set $\alpha=0.05$.

\section{RESULTS}

\section{Seasonal Study}

We obtained 856 survey nights over the course of the seasonal study, accounting for nights when detectors failed as result of malfunctioning $\mathrm{CF}$ cards, failed batteries, or bear disturbance. We recorded 1.17 TB (409,105 sound files) of data. After scrubbing noise files from data, we analyzed
185.57 GB (64,886 files) of data by hand, identifying 21.14 GB (7,392 call files) with animal calls. Of those, 637 were identified as Carolina northern flying squirrel call files. We classified Carolina northern flying squirrel calls as tonal chirps (428), trills (79), upsweeps (60), and barks-yelps (70; Gilley et al. 2019). We did not detect southern flying squirrels at any of our survey sites for this study. We detected Carolina northern flying squirrels during each season: $53.3 \%$ of sites in spring, $56.6 \%$ of sites in summer, and $56.6 \%$ of sites in autumn. Of the sites we surveyed, all but one site had $\geq 1$ night where a Carolina northern flying squirrel was detected over the course of the study, although $83.3 \%$ of sites had $\geq 2$ nights of detections $(4.7 \pm 1.0$; range $=2-13$ ). Five sites detected Carolina northern flying squirrels in all seasons and 16 sites detected them in $\leq 2$ seasons. The POD for each season was $0.30 \pm 0.04$ in spring, $0.25 \pm 0.04$ in summer, and $0.26 \pm 0.04$ in autumn. Although detection rates were slightly greater in spring, they did not differ from the other seasons $\chi_{2}^{2}=0.06$, $P=0.97$; Fig. $3 \mathrm{~A})$. The LTD was similar among seasons: $7.0 \pm 0.8$ nights in spring, $7.8 \pm 0.6$ nights in summer, and $6.8 \pm 0.8$ nights in autumn $\left(\chi_{2}^{2}=0.69, P=0.71\right.$; Fig. 3B).
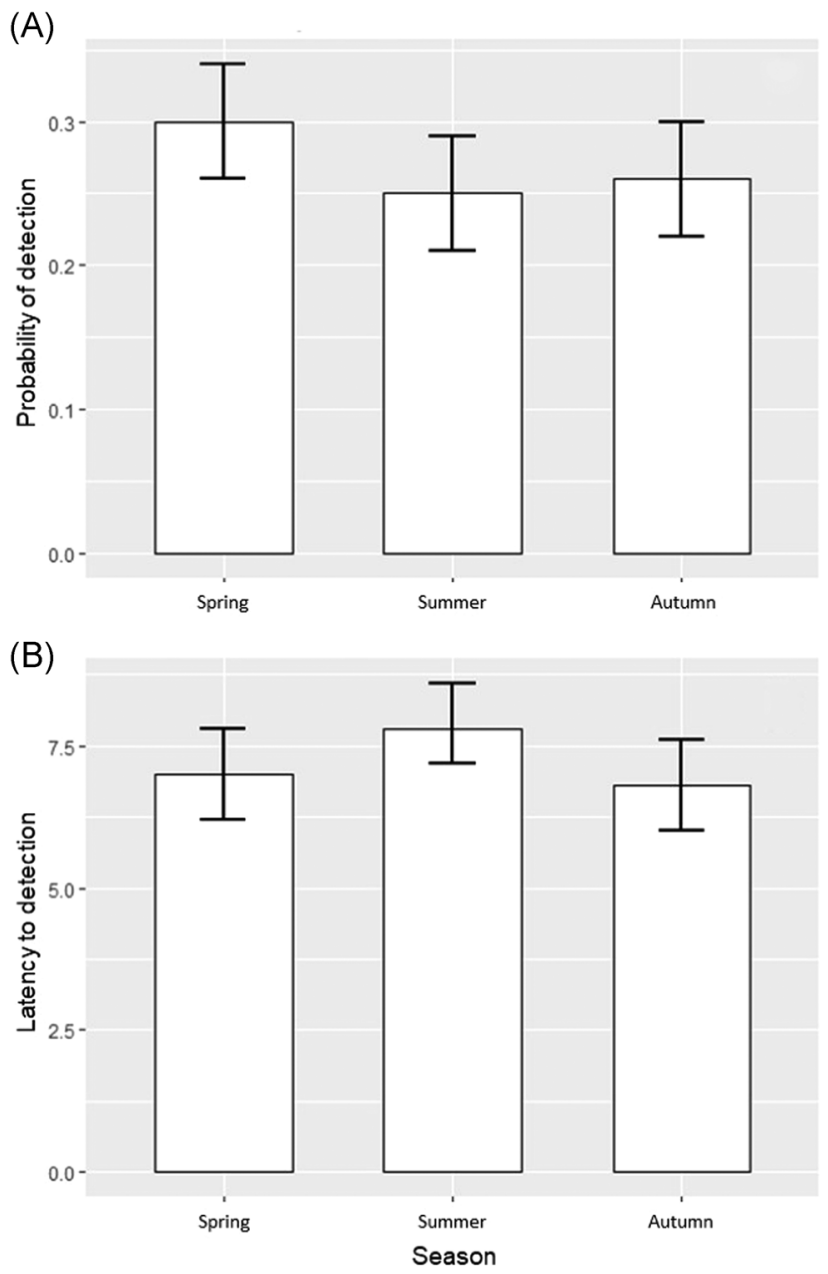

Figure 3. Seasonal averages for probability of detection (A) and latency to detection (B) for Carolina northern flying squirrel during 2015 in western North Carolina, USA. 


\section{Habitat Quality Study}

We obtained 300 survey nights over the course of the habitat quality study with no detector failures. We recorded 295.47 GB (103,311 sound files) of data. Once we scrubbed noise files from the data, we analyzed 55.59 GB $(19,438$ files) of data by hand. We identified 3,894 call files with animal calls, including bats, flying squirrels, and unknown species. We identified 696 flying squirrel call files: 529 Carolina northern flying squirrels, 107 southern flying squirrels, and 60 unidentified flying squirrel species. We recorded the following call types for Carolina northern flying squirrels: 454 trills, 59 tonal chirps, 23 upsweeps, 3 arc chirps, and 2 two-toned chirps. We recorded 15 call files with multiple Carolina northern flying squirrel call types. We recorded the following call types for southern flying squirrels: 96 trills, 9 tonal chirps, 2 yelps, and 1 upsweep. We only recorded one call file with multiple southern flying squirrel call types.

We recorded Carolina northern flying squirrels at 11 of our 15 survey sites, including all 5 High sites, 4 Medium sites, and 2 Low sites. For Carolina northern flying

(A)

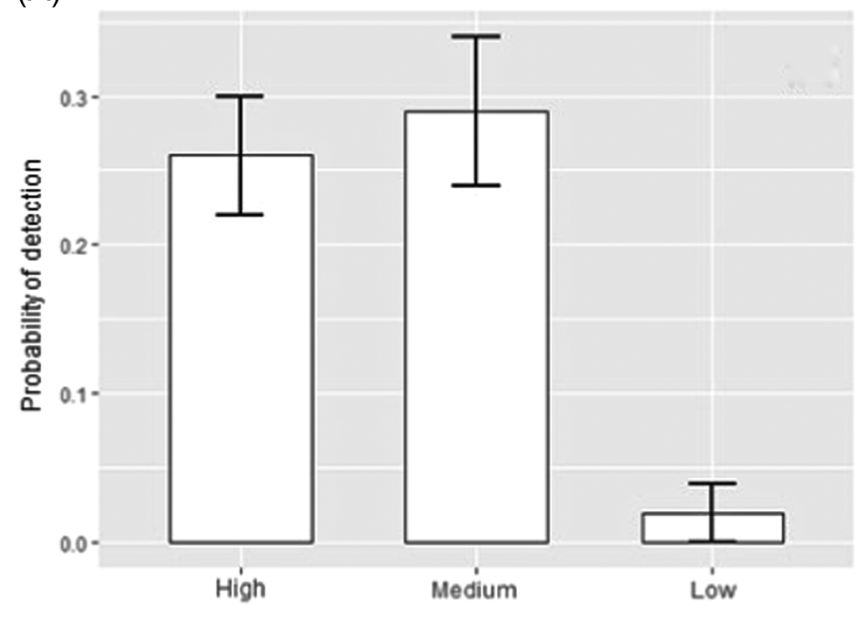

(B)

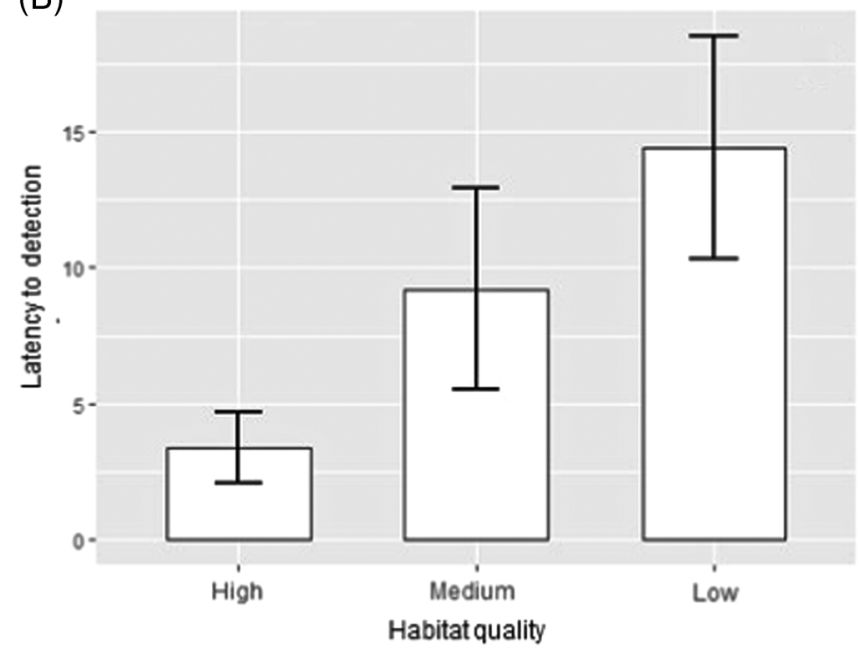

squirrels, POD differed among sites: $0.26 \pm 0.04$ at High sites, $0.29 \pm 0.05$ at Medium sites, and $0.02 \pm 0.02$ at Low sites $\left(\chi_{2}^{2}=7.57, P=0.02\right.$; Fig. 4A). The LTD for Carolina northern flying squirrel was $3.4 \pm 1.3$ nights at the High sites, $9.2 \pm 3.7$ at Medium sites, and $14.4 \pm 4.1$ at Low sites (Fig. 4B). There was no difference in LTD among habitat quality categories $\left(\chi_{2}^{2}=3.61, P=0.16\right)$, although LTD for Low sites was $4.2 \times$ longer than High sites. We recorded southern flying squirrels at 9 of our survey sites, including 1 High site, 3 Medium sites, and 5 Low sites. The POD for southern flying squirrels differed among sites: $0.03 \pm 0.02$ at High sites, $0.17 \pm 0.05$ at Medium sites, and $0.41 \pm 0.05$ at Low sites $\left(\chi_{2}^{2}=9.09, P=0.01\right.$; Fig. $\left.4 \mathrm{C}\right)$. For southern flying squirrels, LTD was $17.4 \pm 3.6$ nights at the High sites, $10.6 \pm 4.3$ at Medium sites, and $2.4 \pm 0.6$ at Low sites (Fig. 4D). The LTD differed among sites for southern flying squirrels $\left(\chi_{2}^{2}=6.29, P=0.04\right)$.

\section{DISCUSSION}

Ultrasonic acoustics is a novel technique that has been used successfully to survey for endangered subspecies of flying

(C)

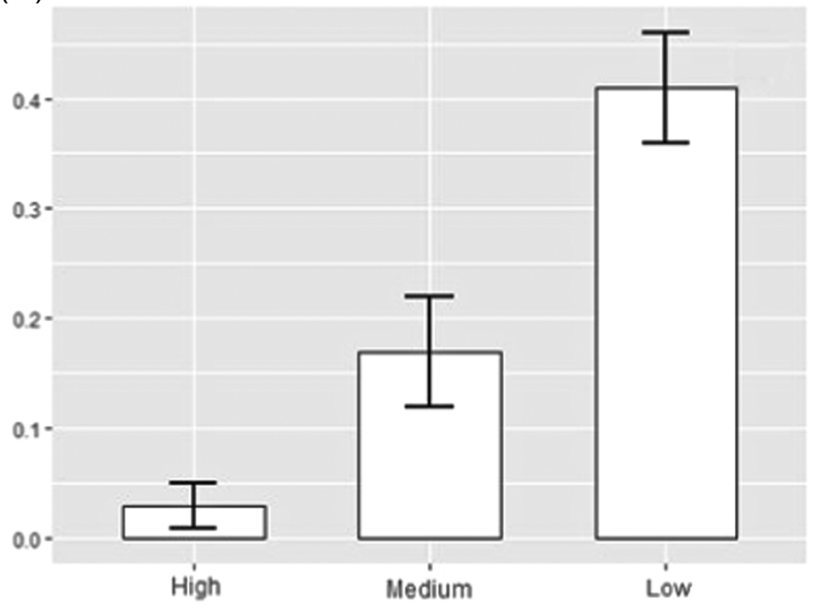

(D)

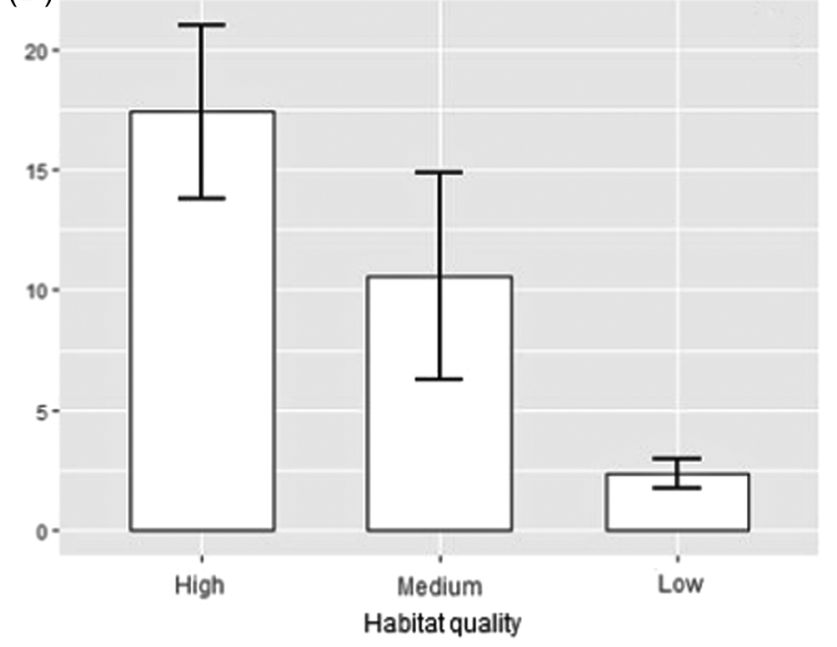

Figure 4. Mean probability of detection (POD) and latency to detection (LTD) for sites with varying habitat quality for flying squirrels during 2015 in western North Carolina, USA. High ( $>50 \%$ habitat availability), Medium (10-50\% habitat availability), and Low ( $<10 \%$ habitat availability) sites. Carolina northern flying squirrels: A) POD and B) LTD. Southern flying squirrels: C) POD and D) LTD. 
squirrels at sites where they are sympatric with another species of flying squirrels (Diggins et al. 2016, Diggins and Ford 2017). Our data suggest that ultrasonic acoustics can be used across a range of seasons to detect flying squirrels, although greater and more efficient detection rates corresponded with increasing habitat quality for Carolina northern flying squirrels.

Flying squirrels are active year round and we detected Carolina northern flying squirrels across all seasons during our seasonal study (Wells-Gosling and Heaney 1984). We detected Carolina northern flying squirrels at $96.7 \%$ of our seasonal sites, but we only detected Carolina northern flying squirrels at $16.7 \%$ of the sites during all 3 seasons. Although there was no statistical difference among seasonal detection rates, we did observe slightly greater detection rate trends in the spring. We have also found similar detection rates during studies in Pennsylvania, USA, and North Carolina during the late spring (i.e., May-Jun; Diggins et al. 2016, Diggins and Ford 2017). In the habitat quality study, which occurred in June, detection rates at High and Medium sites were similar to those in the seasonal study regardless of season. However, in each of these studies, LTD in highquality sites was much lower than in high-quality sites of this seasonal study. The LTD in the seasonal study was similar among seasons and ranged from 6.8 to 7.8 nights, whereas LTDs in other studies conducted in late spring in North Carolina and Pennsylvania were 56-80\% more efficient (Diggins et al. 2016, Diggins and Ford 2017).

Although season did not influence LTD or POD, some call types varied seasonally, especially trills, which are considered species-specific and easily identified to species compared with other call types. Acoustic studies on Carolina northern flying squirrels and northern flying squirrels in Pennsylvania during late spring showed trills as the most common call type recorded, representing 71.6-97.6\% of calls (Diggins et al. 2016, Diggins and Ford 2017). In the seasonal study, trills comprised $12.4 \%$ of the call files recorded, with $27.8 \%$ of trill recorded in summer, $31.6 \%$ in autumn, and $40.5 \%$ in spring. Tonal chirps (i.e., whistles) represented the most common call type recorded during the seasonal study $(65.6 \%)$, but are also the vocalization that can be misidentified with low-frequency bat echolocation pulses of the hoary bat (Lasiurus cinereus; Diggins et al. 2016). Although it is unknown why there are increased trill calls in spring (especially late spring), these vocalizations correspond to the time of year when juvenile northern flying squirrels have matured enough to leave the nest in the central and southern Appalachians (Stihler et al. 1987, Weigl et al. 1992, Reynolds et al. 1999). Trills are produced by both adult and juvenile flying squirrels and hypothesized to be a breeding call and juvenile separation call, but further work is needed to confirm this (L. M. Gilley, personal observation). Even though there was no statistical difference in LTD or detection among seasons, we suggest conducting surveys during late spring in areas where Carolina northern flying squirrels are sympatric with southern flying squirrels because trills are more common during this time period. In areas where only one species is present, surveys may be conducted any time of the year.

Not surprisingly, habitat quality influenced detection rates for Carolina northern flying squirrels and southern flying squirrels, although habitat quality was not assumed to influence detection rates of flying squirrels for traditional lowcapture techniques, such as nest-box surveys (Ford et al. 2010). We obtained the habitat quality classifications for Carolina northern flying squirrels from past range-wide mapping efforts, because, as a federally listed species, it was more important to determine minimum survey length for this species than for the common southern flying squirrel (Ford et al. 2015). We found an inverse relationship in detection rates in relation to habitat quality between Carolina northern flying squirrel and southern flying squirrel. Carolina northern flying squirrels are associated with high-elevation montane conifer forests (Payne et al. 1989; Ford et al. 2014, 2015; Diggins et al. 2017). Lower quality habitat, such as Low sites, have much smaller amounts of overstory montane conifer, whereas High sites were dominated by montane conifers in the overstory. Restricted by colder temperatures at higher elevations, southern flying squirrels are most associated with forests of hard-mast-producing trees, such as oak (Quercus spp.) or American beech and, hence, are most sympatric with the Carolina northern flying squirrel at the spruce-northern hardwood ecotone where hard mast is more readily available (Fridell and Litvaitis 1991, Weigl et al. 1992, Holloway and Malcolm 2007). Additionally, southern flying squirrels typically are not found in stands dominated by montane conifers, although southern flying squirrels occasionally are found in montane conifer stands directly adjacent to northern hardwood stands during summer (Urban 1988; Craig Stihler, West Virginia Department of Natural Resources, personal communication). We found higher quality habitats tended to have greater detection rates; therefore, survey length should be adjusted depending on habitat quality to reduce the probability of estimating a lack of occupancy at a site. Within available habitat, survey periods of 6-10 consecutive survey nights may decrease the probability of a false absence. Additionally, in areas of low habitat quality that are approximate $(<500 \mathrm{~m}$ from conifer dominant stands) to areas of higher quality, we suggest a minimum of $15-20$ consecutive survey nights for monitoring purposes.

The use of ultrasonic acoustics to monitor flying squirrels in the wild is a new technique and although it produces high detection rates, additional methodology needs to be explored to further refine this technique. The effectiveness of acoustic surveys for monitoring and differentiating sympatric species of flying squirrels, especially compared with other survey techniques, has been demonstrated (Gilley 2013, Diggins et al. 2016, Diggins and Ford 2017). However, although our 2 studies helped clarify survey season and length for this technique, we only collected one year of data for each study, so we did not observe annual variation in POD and LTD related to seasonality and habitat quality. Similarly, for the habitat quality study, we had relatively small sample sizes in each habitat quality category, so we 
could survey all sites simultaneously and remove any potential temporal variation. Therefore, our results on survey length in relation to habitat quality should be considered preliminary and are conservatively more suited to annual monitoring programs with repeated surveys versus single visit surveys, which may occur for consultant monitoring prior to construction or silvicultural projects.

Future studies focusing on different factors may aid researchers in improving the use of this survey technique, including expanding on our work with multiyear surveys. For example, detector height may influence detection rates because flying squirrels are arboreal and setting detectors higher than $1.5 \mathrm{~m}$ may influence detection rates. Detector height was an important line of inquiry in developing bat acoustic methodology that would improve detection rates of certain bat species and trap height influenced capture rates of flying squirrels during live-trapping surveys (Loeb et al. 1999, Menzel et al. 2005). Further understanding the configuration and number of detectors on the landscape to determine occupancy at a site may further inform minimal survey effort needed in acoustic study designs to answer certain monitoring or research questions. Multiple types of commercial ultrasonic acoustic detector types are available, but currently we have limited understanding of how detector types influence detection rates of flying squirrels. From pilot studies conducted by the authors, we have found that full spectrum detectors are better than frequency division for recording flying squirrels. However, variation between detector brands and settings of full spectrum detectors may also influence detection rates and needs further analysis. Additionally, active playback surveys may be used to expedite detection rates of flying squirrels at a site and have been preliminary used in field surveys by the senior author. Therefore, we encourage the further development of this technique and its methodology so that a standardized protocol can be employed across a variety of studies at multiple spatial and temporal scales, especially for species of flying squirrels listed as threatened or endangered.

\section{ACKNOWLEGMENTS}

We would like to thank K. Weeks, S. Cameron, M. Crockett, M. McCombs, S. Bryan, E. Corey, R. McGraw, B. Cherry, P. Super, J. Yarkovich, and B. Stiver for logistical support. S. Higdon, K. Parker, A. Garnish, N. Yates, and H. B. Hound provided assistance with field work and data management. The Southern Appalachian Highlands Conservancy provided housing. North Carolina Pittman-Robertson grant \#W-66-R-1, U.S. Fish and Wildlife Endangered Species Recovery Implementation grant \#F11AC01265, and National Park Service Southern Appalachian Cooperative Ecosystem Study Unit agreement \#P12AC13175 provided funding for this project. This research was conducted under North Carolina Wildlife Resources Commission Endangered Species Permit \#14-ES00401, U.S. Fish \& Wildlife Service Endangered Species Research Recovery Permit \#TE34778A-0, North Carolina State Parks Permit \#2015-0023, and National Park Service Permit \#GRSM-2015-SCI-1226. Associate Editor
P. Neuhaus, K. Weeks, S. Hirt, and 2 anonymous reviewers provided comments that helped improve this manuscript. The authors of this manuscript have no known conflicts of interest. The use of trade, product, or firm names does not imply endorsement by the U.S. government.

\section{LITERATURE CITED}

Adams, A. M., M. K. Jantzen, R. M. Hamilton, and M. B. Fenton. 2012. Do you hear what I hear? Implications of detector selection for acoustic monitoring of bats. Methods in Ecology and Evolution 3:992-998.

Boulerice, J. T., and L. A. Van Fleet. 2016. A novel technique for detecting northern flying squirrels. Wildlife Society Bulletin 40:786-791.

Britzke, E. R., E. H. Gillam, and K. L. Murray. 2013. Current state of understanding of ultrasonic detectors for the study of bat ecology. Acta Theriologica 58:109-117.

Britzke, E. R., B. A. Slack, M. P. Armstrong, and S. C. Loeb. 2010. Effects of orientation of weatherproofing on the detection of bat echolocation calls. Journal of Fish and Wildlife Management 1:136-141.

Coleman, L. C., W. M. Ford, C. A. Dobony, and E. R. Britzke. 2014. A comparison of passive and active acoustic sampling for monitoring a bat community impacted by white-nose syndrome. Journal of Fish and Wildlife Management 5:217-226.

Crimmins, S. M., N. M. Roberts, D. A. Hamilton, and A. R. Mynsberge. 2009. Seasonal detection rates of river otters (Lontra canadensis) using bridge-site and random-site surveys. Canadian Journal of Zoology 87:993-999.

Diggins, C. A., and W. M. Ford. 2017. Habitat occupancy and detection rates of northern flying squirrels in Pennsylvania using ultrasonic acoustics. Final Report to Pennsylvania Game Commission, Harrisburg, USA.

Diggins, C. A., L. M. Gilley, C. A. Kelly, and W. M. Ford. 2016. Comparison of survey techniques on detection of northern flying squirrels. Wildlife Society Bulletin 40:654-662.

Diggins, C. A., A. Silvis, C. A. Kelly, and W. M. Ford. 2017. Home range, den selection, and habitat use of Carolina northern flying squirrels (Glaucomys sabrinus coloratus). Wildlife Research 44:427-437.

Eisinger, J. W., J. S. Scheibe, and E. A. Flaherty. 2016. Novel Glaucomys volans vocalizations in Indiana and evidence of geographical variation in high frequency communication. Journal of Mammalogy 97:1219-1227.

Ford, W. M., A. M. Evans, R. H. Odom, J. L. Rodrigue, C. A. Kelly, N. Abaid, C. A. Diggins, and D. Newcomb. 2015. Predictive habitat models derived from nest-box occupancy for the endangered Carolina northern flying squirrel in the southern Appalachians. Endangered Species Research 27:131-140.

Ford, W. M., C. A. Kelly, J. L. Rodrigue, R. H. Odom, D. Newcomb, L. M. Gilley, and C. A. Diggins. 2014. Late winter and early spring home range and habitat use of the endangered Carolina northern flying squirrel in western North Carolina. Endangered Species Research 23:73-82.

Ford, W. M., K. R. Mosey, C. W. Stihler, and J. W. Edwards. 2010. Area occupancy and detection probabilities of the Virginia northern flying squirrel (Glaucomys sabrinus fuscus) using nest-box surveys. Pages 37-47 in J. S. Rentch and T. M. Schuler, editors. Proceedings from the conference on the ecology and management of high elevation forests in the central and southern Appalachian Mountains. U.S. Department of Agriculture Forest Service General Technical Report NRS-P-64, Northern Research Station, Newtown Square, Pennsylvania, USA.

Foster, R. J., and B. R. Harmsen. 2012. A critique of density estimation from camera-trap data. Journal of Wildlife Management 76:224-236.

Fridell, R. A., and J. A. Litvaitis. 1991. Influence of resource distribution and abundance on home-range characteristics of southern flying squirrels. Canadian Journal of Zoology 69:2589-2593.

Froidevaux, J. S. P., F. Zellweger, K. Bollmann, and M. K. Obrist. 2014. Optimizing passive acoustic sampling of bats in forests. Ecology and Evolution 4:4690-4700.

Gibb, R., E. Browning, P. Glover-Kapfer, and K. E. Jones. 2018. Emerging opportunities and challenges for passive acoustics in ecological assessment and monitoring. Methods in Ecology and Evolution 10: $169-185$.

Gilley, L. M. 2013. Discovery and characterization of high-frequency calls in North American flying squirrels (Glaucomys sabrinus and G. volans): implications for ecology, behavior, and conservation. Dissertation, Auburn University, Auburn, Alabama, USA. 
Gilley, L. M., C. A. Diggins, S. M. Pearson, and T. L. Best. 2019. Vocal repertoire of captive northern and southern flying squirrels (Glaucomys sabrinus and G. volans). Journal of Mammalogy 100:518-530.

Glen, A. S., S. Cockburn, M. Nichols, J. Ekanayake, and B. Warburton. 2013. Optimising camera traps for monitoring small mammals. PLoS ONE 8(6):e67940.

Gompper, M. E., R. W. Rays, J. C. Ray, S. D. LaPoint, D. A. Bogan, and J. R. Cryan. 2006. A comparison of noninvasive techniques to survey carnivore communities in northeastern North America. Wildlife Society Bulletin 34:1142-1151.

Gooch, M. M., A. M. Heupel, S. J. Price, and M. E. Dorcas. 2006. The effects of survey protocol on detection probabilities and site occupancy estimates of summer breeding anurans. Applied Herpetology 3:129-142.

Greene, D. U., R. A. McCleery, L. M. Wagner, and E. P. Garrison. 2016. A comparison of four survey methods for detecting fox squirrels in the southeastern United States. Journal of Fish and Wildlife Management 7:99-106.

Gu, W., and R. K. Swihart. 2004. Absent or undetected? Effects of nondetection of species occurrence on wildlife-habitat models. Biological Conservation 116:195-203.

Hayes, J. P. 2000. Assumptions and practical considerations in the design and interpretation of echolocation-monitoring studies. Acta Chiropterologica 2:225-236.

Hines, J. E. 2018. PRESENCE, version 12.24: software to estimate patch occupancy and related parameters. U.S. Geological Survey Patuxent Wildlife Research Center. http://www.mbrpwrc.usgs.gov/software/ presence.html. Accessed 20 Dec 2018.

Holloway, G. L., and J. R. Malcolm. 2007. Northern and southern flying squirrel use of space within home ranges in central Ontario. Forest Ecology and Management 242:747-755.

Kalcounis-Rueppell, M. C., J. D. Metheny, and M. J. Vonhof. 2006. Production of ultrasonic vocalizations by Peromyscus mice in the wild. Frontiers in Zoology 3:3.

Kalcounis-Rueppell, M. C., R. Petric, J. R. Briggs, C. Carney, M. M. Marshall, J. T. Willse, O. Rueppell, D. O. Ribble, and J. P. Crossland. 2010. Differences in ultrasonic vocalizations between wild and laboratory California mice (Peromyscus californicus). PLoS ONE 5(4):e9705.

Kelly, M. J. 2008. Design, evaluate, refine: camera trap studies for elusive species. Animal Conservation 11:182-184.

Loeb, S. C., G. L. Chapman, and T. R. Riley. 1999. Sampling small mammals in southeastern forests: the importance of trapping in trees. Proceedings of the Southeastern Association of Fish and Wildlife Agencies 53:415-424.

MacKenzie, D. I., J. D. Nichols, G. B. Lachmans, S. Droege, J. A. Royle, and C. A. Langtimm. 2002. Estimating site occupancy rates when detection probabilities are less than one. Ecology 83:2248-2255.

MacKenzie, D. I., J. D. Nichols, N. Sutton, K. Kawanishim, and L. L. Bailey. 2005. Improving inferences in population studies of rare species that are detected imperfectly. Ecology 86:1101-1113.

McDonald, L. L. 2004. Sampling rare populations. Pages 11-42 in W. L. Thompson, editor. Sampling rare or elusive species: concepts, designs, and techniques for estimating population parameters. Island Press, Washington, D.C., USA.

McDonald, P. J., A. D. Griffiths, C. E. M. Nano, C. R. Dickmans, S. J. Ward, and G. W. Luck. 2015. Landscape-scale factors determine occupancy of the critically endangered central rock-rat in arid Australia: the utility of camera trapping. Biological Conservation 191:93-100.

Menzel, J. M., M. A. Menzel, J. C. Kilgo, W. M. Ford, J. W. Edwards, and G. F. McCracken. 2005. Effects of habitat and foraging height on bat activity in the Southeastern Coastal Plain. Journal of Wildlife Management 69:235-245.

Muul, I. 1968. Behavioral and physiological influences on the distribution of the flying squirrel, Glaucomys volans. Museum of Zoology Miscellaneous Publication 134, University of Michigan, Ann Arbor, USA.
Payne, J. L., D. R. Young, and J. F. Pagels. 1989. Plant community characteristics associated with the endangered northern flying squirrel, Glaucomys sabrinus, in the southern Appalachians. American Midland Naturalist 121:285-292.

Petric, R., and M. C. Kalcounis-Rueppell. 2013. Female and male adult brush mice (Peromyscus boylii) use ultrasonic vocalizations in the wild. Behavior 150:1747-1766.

Pollock, K. H., J. D. Nichols, T. R. Simons, G. L. Farnsworth, L. L. Bailey, and J. R. Sauer. 2002. Large scale wildlife monitoring studies: statistical methods for design and analysis. Environmetrics 13:105-119.

R Development Core Team. 2015. R: a language and environment for statistical computing. R Foundation for Statistical Computing, Vienna, Austria.

Reynolds, R. J., J. F. Pagels, and M. L. Fies. 1999. Demography of northern flying squirrels in Virginia. Proceedings of the Southeastern Association of Fish and Wildlife Agencies 53:340-349.

Sales, G. D. 2010. Ultrasonic calls of wild and wild-type rodents. Pages 77-88 in S. M. Brudzynski, editor. Handbook of mammalian vocalizations: an integrative neuroscience approach. Academic Press, London, England, United Kingdom.

Soltis, J., C. A. Alligood, T. E. Bowers, and A. Savage. 2012. The vocal repertoire of the Key Largo woodrat (Neotoma floridana smalli). Journal of Acoustical Society of America 132:3350-3558.

Stihler, C. W., K. B. Knight, and V. K. Urban. 1987. The northern flying squirrel in West Virginia. Pages 176-183 in R. R. Odum, K. A. Riddleberger, and J. C. Dozier, editors. Proceedings of the third Southeast nongame and endangered wildlife symposium. University of Georgia, Athens, USA.

Taylor, B. D., R. L. Goldingay, and J. M. Lindsay. 2014. Horizontal or vertical? Camera trap orientations and recording modes for detecting potorros, bandicoots, and pademelons. Australian Mammalogy 36:60-66.

U.S. Endangered Species Act of 1973, as amended, Pub. L. No. 93-205, 87 Stat. 884 (Dec. 28, 1973). http://www.fws.gov/endangered/esa-library/ pdf/ESAall.pdf

U.S. Fish and Wildlife Service [USFWS]. 1985. Final rule for listing Carolina flying squirrels and Virginia flying squirrels as endangered. 50 FR 27002, 1 Jul 1985.

U.S. Fish and Wildlife Service [USFWS]. 1990. Appalachian northern flying squirrel (Glaucomys sabrinus fuscus and Glaucomys sabrinus coloratus) recovery plan. U.S. Fish and Wildlife Service, Annapolis, Maryland, USA.

Urban, V. K. 1988. Home range, habitat utilization, and activity of the endangered northern flying squirrel. Thesis, West Virginia University, Morgantown, USA.

Vine, S. J., M. S. Crowther, S. J. Lapidge, C. R. Dickman, N. Mooney, M. P. Piggott, and A. W. English. 2009. Comparison of methods to detect rare and cryptic species: a case study using the red fox (Vulpes vulpes). Wildlife Research 36:436-446.

Weigl, P. D., T. W. Knowles, and A. C. Boyton. 1992. The distribution and ecology of the northern flying squirrel, Glaucomys sabrinus coloratus, in the southern Appalachians. North Carolina Wildlife Resources Commission Publication, Raleigh, USA.

Weller, T. J., and C. J. Zabel. 2002. Variation in bat detections due to detector orientation in a forest. Wildlife Society Bulletin 30:922-930.

Wells-Gosling, N. 1985. Flying squirrels: gliders in the dark. Smithsonian Institution Press, Washington, D.C., USA.

Wells-Gosling, N., and L. R. Heaney. 1984. Glaucomys sabrinus. Mammalian Species 229:1-8.

Wilson, D. R., and J. F. Hare. 2006. The adaptive utility of Richardson's ground squirrel (Spermophilus richardsonii) short-range ultrasonic alarm signals. Canadian Journal of Zoology 84:1332-1330.

Associate Editor: Neuhaus. 